\title{
LICENCIATURAS EM CIÊNCIAS BIOLÓGICAS: ANÁLISE DE CURRÍCULOS DE FORMAÇÃO DE PROFESSORES PARA O ENSINO DE CIÊNCIAS E BIOLOGIA
}

\author{
PROFESORADOS EN CIENCIAS BIOLÓGICAS: ANÁLISIS DE CURRÍCULOS DE \\ FORMACIÓN DEL PROFESORADO PARA LA ENSEÑNANZA DE CIENCIAS Y \\ BIOLOGIA
}

\author{
BIOLOGICAL SCIENCE LICENTIATE DEGREES: ANALYSIS OF TEACHER \\ TRAINING CURRICULUM FOR TEACHING SCIENCE AND BIOLOGY
}

\author{
Emerson Augusto de MEDEIROS ${ }^{1}$ \\ Mário Luan Silva de MEDEIROS ${ }^{2}$
}

\begin{abstract}
RESUMO: Este texto tem como objetivo apresentar uma análise de currículos de formação de professores para o ensino de ciências e biologia nos anos finais do Ensino Fundamental e no Ensino Médio, tomando como parâmetro oito Licenciaturas em Ciências Biológicas de universidades públicas dos Estados do Ceará, Paraíba e Rio Grande do Norte. A partir da análise documental, caracterizamos as matrizes curriculares dispostas nos Projetos Pedagógicos dos Cursos. Concluímos, entre outros pontos, que as matrizes curriculares apresentam uma variedade de disciplinas e áreas científicas, porém, algumas delas estão secundarizadas nos currículos, como a Ecologia e as disciplinas das áreas de ciências sociais e humanas. Em relação às disciplinas de cunho pedagógico, a partir da análise, evidenciamos dois eixos principais: o primeiro se concentra em disciplinas que enfatizam as questões acerca do saber ensinar ciências e biologia; e o segundo aborda a Educação, com disciplinas que a situam para além do ensino e da sala de aula.
\end{abstract}

PALAVRAS-CHAVE: Licenciaturas em ciências biológicas. Currículo. Formação de professores. Ensino de ciências e biologia.

RESUMEN: Este texto tiene por objetivo presentar un análisis de currículos de formación del profesorado para la enseñanza de ciencias y biología en los años finales de la Enseñanza Primaria y en la Enseñanza Media, tomando como parámetro ocho Profesorados en Ciencias Biológicas de universidades públicas de los Estados Ceará, Paraíba y Río Grande del Norte. A partir del análisis documental, caracterizamos las matrices curriculares dispuestas en los Proyectos Pedagógicos de los Cursos. Concluimos, entre otros puntos, que las matrices curriculares presentan una variedad de asignaturas y áreas científicas, pero, algunas de ellas están puestas en los currículos, como la Ecología y las asignaturas de las áreas de ciencias sociales y humanas. Con relación a las asignaturas de sesgo pedagógico, a partir del

\footnotetext{
1 Universidade Federal Rural do Semi-Árido (UFERSA), Mossoró - RN - Brasil. Professor Adjunto do Departamento de Ciências Humanas. Doutorado em Educação (UECE). ORCID: https://orcid.org/0000-00033988-3915. E-mail: emerson.medeiros@ufersa.edu.br

${ }^{2}$ Universidade do Estado do Rio Grande do Norte (UERN), Mossoró - RN - Brasil. Professor Auxiliar do Departamento de Ciências Biomédicas. Doutorado em Bioquímica e Biologia Molecular (UERN). ORCID: https://orcid.org/0000-0002-5720-6953. E-mail: mariolsmedeiros@gmail.com
} 
análisis, evidenciamos dos principales ejes: el primero se enfoca en asignaturas que enfatizan preguntas sobre cómo enseñar ciencia y biología; y el segundo aborda la Educación, con asignaturas que la sitúan más allá de la enseñanza y del aula.

PALABRAS CLAVE: Profesorados en Ciencias Biológicas. Currículo. Formación del profesorado. Enseñanza de ciencias y biología.

ABSTRACT: This paper aims to present an analysis of teacher training curriculum for the teaching of science and biology in the final years of elementary school and high school, taking as its parameter eight degrees in Biological Sciences from public universities in the states of Ceará, Paraiba and Rio Grande do Norte. Starting from the documentary analysis, we characterize the curricular matrices arranged in the Pedagogical Projects of the Courses. We concluded, among other points, that the curricular matrices present a variety of subjects and scientific areas, however, some of them are secondary in the curricula, such as Ecology and the disciplines of social sciences and humanities. With regard to pedagogical disciplines, from the analysis, we highlight two main axes: the first focuses on disciplines that emphasize the issues of how to teach science and biology; and the second addresses Education, with disciplines that situate it beyond teaching and the classroom.

KEYWORDS: Biological science licentiate degrees. Curriculum. Teacher training. Teaching of science and biology.

\section{Introdução}

$\mathrm{Na}$ literatura acadêmica educacional brasileira, há inúmeros estudos que enfatizam que, na história da formação de professores no Brasil, nos cursos de licenciatura específicos (Química, Matemática, Língua Portuguesa, História, Geografia, para citar alguns), o predomínio dos conhecimentos e dos conteúdos disciplinares se fez como a marca central nas propostas curriculares das graduações. Entretanto, há pouca atenção aos conhecimentos e aos conteúdos curriculares voltados à área de Educação (AYRES, 2005; GATTI; BARRETTO, 2009; GATTI; NUNES, 2009; MEDEIROS, 2017; MEDEIROS; AGUIAR, 2018).

No contexto dos cursos de Licenciatura em Ciências Biológicas, não é diferente, afinal, a predominância de uma formação docente dissociada da realidade educacional e de sua complexidade configurou na história o que se nomina de "formação bacharelesca" (GATTI; NUNES, 2009). A ênfase direcionada, nos currículos das graduações, aos conhecimentos e aos conteúdos curriculares das disciplinas que compõem as Ciências Biológicas (Parasitologia, Genética, Zoologia, Anatomia, Microbiologia, entre outras), sem a devida articulação com a sala de aula no Ensino Básico, predominou na formação dos professores. Estes, mesmo concluindo a licenciatura, conhecem pouco a Educação e não 
conseguem desenvolver, por vezes, uma leitura crítico-reflexiva acerca do âmbito profissional em que atuarão (AYRES; SELLES, 2012; FEITOSA, 2014; MEDEIROS, 2017).

Como consequência do cenário apontado no parágrafo anterior, o ensino de ciências, nos anos finais do Ensino Fundamental, e de Biologia, no Ensino Médio, permeou-se, na maior parte da história da Educação Básica no Brasil, de abordagens acríticas, conteudistas e apartadas das questões sociais, ambientais, geracionais, culturais, econômicas, entre outras, importantes para o desenvolvimento social do País e dos sujeitos em formação (AYRES; SELLES, 2012; FEITOSA, 2014; MEDEIROS, 2017).

Este texto tem como objetivo apresentar uma análise de currículos de formação de professores para o ensino de ciências e biologia nos anos finais do Ensino Fundamental e no Ensino Médio, tomando como parâmetro oito (08) Cursos de Licenciatura em Ciências Biológicas de universidades públicas dos Estados do Ceará (03), Paraíba (03) e Rio Grande do Norte (02). Em pormenores, buscamos (a.) caracterizar as matrizes curriculares dispostas nos Projetos Pedagógicos dos Cursos (PPCs) quanto à organização das disciplinas curriculares, com seus conhecimentos e conteúdos curriculares; (b.) bem como evidenciar a organização das disciplinas curriculares voltadas à formação pedagógica para o ensino de ciências e biologia na Educação Básica - anos finais do Ensino Fundamental e Ensino Médio.

Dessa forma, o estudo se associa às produções científicas educacionais que investigam os currículos oficiais de formação docente, concebidos neste texto como prescrições humanas institucionalizadas nos diferentes contextos de educação formal brasileiros (SILVA, 1990; SACRISTÁN, 2013; MEDEIROS, 2019). Os currículos oficiais agregam diferentes concepções científicas, fundamentos políticos e ideológicos, bem como conhecimentos e conteúdos produzidos e sistematizados pela humanidade para serem ensinados (AYRES, 2005; APPLE, 2006). Nos cursos de licenciatura, imprimem, por via dos diferentes documentos curriculares, a exemplo do Projeto Pedagógico de Curso (PPC), o que se objetiva para a formação profissional dos licenciandos.

Em termos metodológicos, destacamos que o estudo se baseia na análise documental de oito (08) Projetos Pedagógicos de Cursos de Licenciatura em Ciências Biológicas das seguintes Instituições Públicas de Educação Superior: Universidade Federal do Ceará (UFC); Universidade Federal do Cariri (UFCA); Universidade da Integração Internacional da Lusofonia Afro-Brasileira (UNILAB); Universidade Federal do Rio Grande do Norte (UFRN); Universidade do Estado do Rio Grande do Norte (UERN); Universidade Federal da Paraíba (UFPB); Universidade Federal de Campina Grande (UFCG) e Universidade Estadual da Paraíba (UEPB). 
Para a constituição do material de análise com os PPCs das Licenciaturas em Ciências Biológicas das universidades supracitadas, consideramos a literatura acadêmica educacional a respeito da formação docente e os documentos normativos sobre a formação de professores da Educação Básica no Brasil. Dentre eles, podemos citar a Resolução CNE/CP no 2, de 20 de dezembro de 2019, que definiu novas Diretrizes Curriculares Nacionais para a Formação Inicial de Professores para a Educação Básica e instituiu a Base Nacional Comum para a Formação Inicial de Professores da Educação Básica (BNC-Formação) (BRASIL, 2019).

Entendemos que, apesar de a produção científica acerca da formação de professores da Educação Básica no Brasil já ter apontado considerações relevantes aos currículos oficiais de formação docente (AYRES, 2005; GATTI; BARRETTO, 2009; GATTI; NUNES, 2009; MEDEIROS; AGUIAR, 2018; REIS; MORTIMER, 2020), ainda há, no caso dos currículos das Licenciaturas em Ciências Biológicas, questões importantes a pensarmos sobre a formação docente. Particularmente, questões que condizem às proposições curriculares destinadas à formação do professor para atuação no ensino de ciências e biologia. Também consideramos que, com a publicação recente do documento normativo que definiu as Diretrizes Curriculares Nacionais para a Formação Inicial de Professores para a Educação Básica e instituiu a Base Nacional Comum para a Formação Inicial de Professores da Educação Básica (BNC-Formação) (BRASIL, 2019), estudos acerca dos currículos dos cursos de licenciaturas são, além de relevantes, necessários e viáveis.

Traçada esta introdução, organizamos o restante do texto em quatro seções. No primeiro momento, abordamos, sucintamente, a formação de professores no Brasil, sua história e base normativa, com ênfase na formação docente para o ensino de ciências e biologia nos anos finais do Ensino Fundamental e no Ensino Médio. Na segunda seção, discutimos sobre os aspectos metodológicos referentes a este estudo. No terceiro momento, apresentamos a análise desenvolvida a partir do que atestam, em termos curriculares, os Projetos Pedagógicos dos Cursos de Licenciatura em Ciências Biológicas. Na seção final, dialogamos acerca das considerações apreendidas nesta investigação.

\section{A formação de professores para o ensino de ciências e biologia no Brasil - breve histórico}

Segundo Gatti e Barretto (2009), quando olhamos a história da formação de professores das disciplinas específicas da Educação Básica no Brasil, surgem, inevitavelmente, questionamentos: "professor de História ou historiador?"; "bacharel em 
Biologia ou licenciado em Biologia?”; “químico ou professor de Química?”; “professor de Geografia ou especialista em Geografia?". Para as autoras, esses questionamentos acompanham, rotineiramente, as produções científicas acerca da formação docente para atuação nos anos finais do Ensino Fundamental e no Ensino Médio.

Isso acontece, na perspectiva das pesquisadoras, por várias razões ${ }^{3}$, porém, no nosso entendimento, há um motivo principal: a formação de professores da Educação Básica no País sempre esteve condicionada aos arranjos e aos interesses de grupos sociais e políticos. Estes, a partir de inúmeras práticas sociais guiadas por fatores econômicos e do mercado industrial (especialmente o mercado industrial internacional), conduziram diferentes políticas educacionais e legislações curriculares que interferiram nos cursos de formação, em sua organização curricular e nos contextos (faculdades, centros superiores de formação, institutos e universidades) em que se sucede a formação docente.

Em verdade, ao associarmos as considerações de Gatti e Barretto (2009) à história da formação de professores para o ensino de ciências e biologia no País (considerando os anos finais do Ensino Fundamental e o Ensino Médio), veremos que ela se promoveu tendo como indicador principal o contexto social e político de cada tempo histórico. Isto é, cada fase social e política na história do Brasil demandou um determinado tipo de ensino que, por sua vez, definiu o perfil de professor e o modelo de currículo e de formação docente a ser seguido.

Validando esses aspectos, o estudo de doutoramento de Ayres (2005) destaca que o primeiro curso, a nível superior, para a formação dos professores do ensino secundário, correspondente atualmente aos anos finais do Ensino Fundamental e ao Ensino Médio, somente aconteceu com a criação das Faculdades de Filosofia ${ }^{4}$, a partir do ano de 1939.

Por meio do Decreto Lei n ${ }^{\circ} 1.190$, de 04 de abril de 1939, originaram-se as Faculdades de Filosofia que, articuladas a um projeto social de País, que tinha por objeção qualificar mão de obra para suprir as demandas profissionais do crescente "Brasil urbano-industrial"1", deram início à construção pelo território nacional dos cursos de licenciatura na Educação Superior. Nesse rol, nasceram os cursos de História Natural ${ }^{6}$, perspectivando a formação de professores para o ensino de ciências e biologia do antigo ensino secundário.

\footnotetext{
${ }^{3}$ As pesquisadoras ressaltam a ausência de clareza, por parte das instituições que formam professores, acerca da identidade dos cursos de licenciatura, a qual condiz com a formação profissional para o exercício da docência na Educação Básica.

${ }^{4}$ Em alguns Estados do País, as Faculdades de Filosofia ganharam outra nominação, a exemplo das Faculdades de Filosofia, Ciências e Letras (MEDEIROS, 2019).

${ }^{5}$ Termo utilizado por Ayres (2005) para se referir à expansão industrial vivenciada pelo Brasil a partir da década de 1930, com forte predomínio do êxodo rural.

${ }^{6} \mathrm{Na}$ literatura especializada que discorre sobre a formação de professores para o ensino de ciências e biologia, não há um consenso acerca do ano de criação do Curso de História Natural. Em Ayres (2005), por exemplo,
} 
Vale lembrar que o Curso de História Natural, tal como os demais cursos que visavam formar professores para o ensino secundário (equivalente no momento aos anos finais do Ensino Fundamental e ao Ensino Médio), era composto por quatro anos, organizados em dois períodos: o primeiro, formado por três anos de estudos, era constituído pelas disciplinas específicas, como Biologia, Química, Física, Geologia, entre outras; o segundo período, de um ano, era composto pelas disciplinas de formação profissional, entendidas como as disciplinas pedagógicas - psicologia educacional, didática geral, didática específica, fundamentos sociológicos, organização do ensino secundário, entre outras (AYRES, 2005).

Ressaltamos que o Curso de História Natural não era entendido, em sua totalidade, como uma licenciatura. Com a conclusão dos três primeiros anos, a formação vivenciada pelo formando o oportunizava ser reconhecido socialmente como bacharel, assim, somente com a finalização do quarto ano de formação, com as disciplinas pedagógicas, ele recebia o grau de licenciado. É essa perspectiva de formação docente concebida nacionalmente como o modelo $3+1$ (três mais um) de formação de professores que se perpetuou nos cursos de licenciatura das disciplinas específicas e que também é reconhecida como "formação bacharelesca".

O Curso de História Natural, tendo seu nascimento nas Faculdades de Filosofia, só adquire nova nomenclatura por volta dos anos de $1960^{7}$, a partir da divisão da graduação em dois cursos: Geologia e Ciências Biológicas. Essa divisão se deu pelo entendimento do Conselho Federal de Educação (CFE), órgão responsável no período histórico pelo reconhecimento dos cursos de graduação, da profissão de geólogo, o que exigia um curso específico para a formação do profissional (TOMITA, 1990). Mesmo mudando sua nomenclatura para Ciências Biológicas, não houve, segundo Tomita (1990) e Ayres (2005), mudanças significativas no modelo 3+1 (três mais um) de formação docente no interior desse curso.

Outro aspecto importante a enfatizarmos nesta seção se refere ao fato de que, no início da década de 1970, mais precisamente com a publicação da Lei $n^{0}$ 5.692, de 11 de agosto de 1971, com a forte demanda por professores para atuar no ensino secundário, houve a criação dos cursos de Licenciatura Curta $^{8}$. Essas graduações, de caráter polivalente, habilitavam professores por disciplinas no período de três anos de estudos. Em referência à formação dos

salienta-se que o primeiro curso nasceu logo após a criação da Universidade de São Paulo (USP), no ano de 1934, porém, sem muito sucesso. Sua expansão se deu somente após a publicação do Decreto Lei no 1.190 , de 04 de abril de 1939, que possibilitou a criação de cursos de formação de professores, a nível superior, pelo Brasil, com a fundação das Faculdades de Filosofia. Esses cursos predominaram em instituições privadas.

${ }^{7}$ Tomita (1990) destaca o ano de 1963.

${ }^{8}$ Entendemos que as Licenciaturas Curtas são frutos das mudanças na Educação Superior oriundas das determinações pontuadas na primeira Lei de Diretrizes e Bases da Educação Nacional, Lei nº 4.024, de 20 de dezembro de 1961, bem como da Reforma Universitária, Lei nº 5.540, de 28 de novembro de 1968. 
docentes para atuação nas disciplinas de ciências e biologia, demandou a criação do Curso de Licenciatura Curta em Ciências ${ }^{9}$ que poderia habilitar, dependendo do contexto e da proposta curricular de formação, os professores em Matemática, Física, Química e Biologia.

Nessa fase histórica (década de 1970), vemos, nitidamente, duas perspectivas de cursos de formação de professores para o ensino de ciências e biologia (voltados ao ensino secundário - equivalente no momento aos anos finais do Ensino Fundamental e ao Ensino Médio): o primeiro, concebido como Licenciatura em Ciências Biológicas ${ }^{10}$, de caráter pleno, com duração de 04 anos; e o segundo, entendido como Licenciatura Curta em Ciências, com a habilitação em Biologia, com duração de três anos.

No entanto, com o fim do regime militar no Brasil e com a promulgação da Constituição Federal, no ano de 1988, a qual deu condições para a instituição da Lei n 9.394 , de 20 de dezembro de 1996, que estabeleceu as novas Diretrizes e Bases da Educação Nacional, as Licenciaturas Curtas foram extintas, prevalecendo as Licenciaturas Plenas em Ciências Biológicas. A partir da instituição desse documento normativo, alguns dispositivos legais curriculares foram estabelecidos para os cursos de formação de professores da Educação Básica, respingando nos cursos de formação dos docentes para o ensino de ciências e biologia.

No que toca às Licenciaturas em Ciências Biológicas, de modo particular, estabeleceuse o Parecer CNE/CES n $n^{0} 1.301$, de 06 de novembro de 2001, que auferiu as diretrizes curriculares nacionais específicas para as graduações em Ciências Biológicas ${ }^{11}$. Essas diretrizes tentaram, parcialmente, destacar encaminhamentos para a organização curricular das graduações.

Na sequência, houve a instituição das primeiras Diretrizes Curriculares Nacionais para os Cursos de Licenciatura, de forma geral. Por intermédio da Resolução CNE/CP nº 01, de 18 de fevereiro de 2002, e da Resolução CNE/CP no 2, de 19 de fevereiro de 2002, instituíram-se tais diretrizes, significando documentos orientadores para todos os cursos de formação de professores do País.

\footnotetext{
${ }^{9}$ A partir do estudo de Reis e Mortimer (2020), entendemos que o nome e o modelo de curso das Licenciaturas Curtas em Ciências deram margem para o nascimento das Licenciaturas em Ciências Naturais ou Ciências da Natureza que, também de caráter polivalente, objetivam a formação de professores para mais de uma disciplina do currículo escolar da Educação Básica, a saber: Ciências; Biologia; Química e Física.

10 A pesquisa de Ayres (2005) aponta o entendimento de que as Licenciaturas em Ciências Biológicas, em algumas instituições educacionais, foram registrados na história (e ainda são) com a nominação de Licenciatura em Biologia. Compreendemos que, talvez, essa variação na nomenclatura seja uma expressão de conceber o referido curso, ora formando docentes apenas para o Ensino Médio (Licenciaturas em Biologia), ora formando docentes para os anos finais do Ensino Fundamental e Ensino Médio (Licenciaturas em Ciências Biológicas).

${ }^{11} \mathrm{O}$ referido documento atesta orientações tanto para as licenciaturas quanto para os cursos de bacharelado.
} 
Apesar das críticas empreendidas por pesquisadores e entidades educacionais a essas diretrizes, em consequência da ênfase dada ao desenvolvimento das competências nos processos de formação docente, alinhando-se aos ditames do mercado industrial global, conseguiu-se, enfim, um documento que estabelecesse diretamente em nível nacional, aos cursos de licenciatura, princípios, fundamentos e procedimentos a serem observados nas propostas curriculares das graduações que vislumbram formar professores para o Ensino Básico.

Em 2015, depois de muitos esforços e lutas desenvolvidas por diferentes segmentos da área de Educação, tais como a Associação Nacional de Pós-Graduação e Pesquisa em Educação (ANPED), a Associação Nacional pela Formação dos Profissionais da Educação (ANFOPE) e o Fórum Nacional dos Diretores das Faculdades, Institutos e Centros de Educação de Universidades Públicas Brasileiras (FORUMDIR), também se instituíram novas Diretrizes Curriculares Nacionais para a Formação Inicial e Continuada dos Profissionais do Magistério da Educação Básica, a Resolução CNE/CP nº 2, de 01 de julho de 2015.

Segundo Dourado (2015), nessas novas Diretrizes, diferentemente das anteriores (publicadas em 2002), concebeu-se a formação inicial e a formação continuada como momentos indissociáveis da formação do professor - apesar de acontecerem em etapas distintas - visando à sua valorização. Além disso, reforçou-se que a valorização dos profissionais do magistério da Educação Básica se dará por via de outras dimensões, tais como carreira, salário e condições de trabalho, associadas também à formação - inicial e continuada.

No ano de 2019, frente a novos embates na agenda política e governamental do Brasil, na intenção de controle social da população por parte do Estado - o que implica no controle da Educação e da formação docente -, as diretrizes publicadas em 2015 foram revogadas por via da Resolução CNE/CP no 2, de 20 de dezembro de 2019. Esta demarcou outras Diretrizes Curriculares Nacionais para a Formação Inicial de Professores para a Educação Básica e instituiu a Base Nacional Comum para a Formação Inicial de Professores da Educação Básica (BNC-Formação).

Pelos apontamentos destacados até então, entendemos que a formação de professores para o ensino de ciências e biologia nos cursos de licenciatura passou por diferentes perspectivas ao longo da história no País que, em momentos, referenciaram avanços aos currículos de formação docente (como a promulgação das diretrizes curriculares nacionais publicadas em 2015) e, em outros períodos, atestaram retrocessos (como as licenciaturas curtas, entre outros). Diante do cenário descrito nesta seção, é preciso destacar, mais uma vez, 
que as perspectivas de formação docente, orientadas por diferentes legislações curriculares, se fizeram com base em interesses de grupos sociais e políticos que assolaram o Brasil. Tudo isso apresenta implicações nos currículos das licenciaturas que, gradativamente, contribuem para a formação da identidade profissional dos professores das escolas brasileiras de Educação Básica.

\section{Metodologia}

Em virtude de o objetivo desta pesquisa se referir a apresentar uma análise de currículos de formação de professores para o ensino de ciências e biologia nos anos finais do Ensino Fundamental e no Ensino Médio, tomando como parâmetro cursos de Licenciatura em Ciências Biológicas de universidades públicas dos Estados do Ceará, Paraíba e Rio Grande do Norte, com relevo para: a (a.) caracterização das matrizes curriculares dispostas nos Projetos Pedagógicos dos cursos (PPCs) quanto à organização das disciplinas curriculares, com seus conhecimentos e conteúdos curriculares; bem como (b.) evidenciar a organização das disciplinas curriculares voltadas à formação pedagógica para o ensino de ciências e biologia na Educação Básica (anos finais do Ensino Fundamental e Ensino Médio), realizamos os seguintes procedimentos metodológicos.

No primeiro momento, fizemos o levantamento na Base de Dados do e-MEC das universidades públicas dos Estados do Ceará, da Paraíba e do Rio Grande do Norte que ofertam as Licenciaturas em Ciências Biológicas como graduações regulares. Nesse momento, encontramos onze (11) instituições (seis federais e cinco estaduais), a saber: Universidade Federal do Ceará (UFC); Universidade Estadual do Ceará (UECE); Universidade Regional do Cariri (URCA); Universidade Vale do Acaraú (UVA); Universidade Federal do Cariri (UFCA); Universidade da Integração Internacional da Lusofonia Afro-Brasileira (UNILAB); Universidade Federal do Rio Grande do Norte (UFRN); Universidade do Estado do Rio Grande do Norte (UERN); Universidade Federal da Paraíba (UFPB); Universidade Federal de Campina Grande (UFCG) e Universidade Estadual da Paraíba (UEPB).

Ao término desse procedimento, como segundo momento, visitamos os sites institucionais das universidades destacadas no parágrafo anterior e buscamos identificar o número de cursos existentes em cada uma delas e em seus campi. Depois desse procedimento, iniciamos a seleção dos Projetos Pedagógicos de Curso (PPCs) disponíveis nas páginas institucionais. Das onze (11) universidades públicas situadas nos Estados do Ceará, Paraíba e 
Rio Grande do Norte que ofertam as Licenciaturas em Ciências Biológicas como graduações regulares, três (03) instituições estaduais do Ceará não disponibilizaram informações quanto à existência dos documentos curriculares (UVA, UECE e URCA). Tal fato nos levou a não incluí-las na pesquisa.

No todo, selecionamos oito (08) Projetos Pedagógicos de Curso (PPCs) que, individualmente, representam uma licenciatura de cada universidade pública selecionada. Esclarecemos que, na UFPB e na UFCG, há cursos situados em mais de um campus, porém, se encontraram disponíveis somente os PPCs das Licenciaturas em Ciências Biológicas dos Campi UFPB/João Pessoa e UFCG/Cajazeiras. Nesse sentido, os documentos curriculares selecionados representam um curso de cada instituição.

No terceiro instante, realizamos a leitura dos documentos curriculares oficiais, com atenção especial para as matrizes curriculares e para os ementários das disciplinas que as compõem, perspectivando concretizar o objetivo principal da pesquisa. Com esse procedimento, organizamos as informações dispostas nos Projetos Pedagógicos dos Cursos (PPCs), em termos quantitativos, em dois quadros e um gráfico, visando à interpretação e análise qualitativa.

Por último, no quarto momento, desenvolvemos a análise qualitativa, a partir das informações disponíveis nos quadros e no gráfico, no intento de empreendermos reflexões a respeito do propósito inicial desta investigação.

\section{Licenciaturas em Ciências Biológicas - organização curricular e formação docente}

Antes de concentrarmo-nos na análise curricular dos Projetos Pedagógicos das Licenciaturas em Ciências Biológicas das universidades públicas dos Estados do Ceará, Paraíba e Rio Grande do Norte, apresentaremos algumas considerações iniciais acerca dos cursos analisados. Em primeiro lugar, das oito (08) Licenciaturas selecionadas, seis (06) se localizam nos campi sedes das instituições (UFC, UNILAB, UERN, UFRN, UEPB e UFPB), o que denota a predominância dessa modalidade de licenciatura em contextos mais centrais das instituições, bem como nas capitais dos três Estados.

Além dessa característica, das oito (08) graduações, somente um curso (01), da UFCA, tem suas atividades de ensino desenvolvidas no turno noturno. As demais licenciaturas funcionam em dois turnos (são cursos diurnos), no período matutino ou de modo integral (manhã, tarde e noite). Também destacamos que, do conjunto de cursos analisados, apenas 
dois (02), das instituições UFC e UFCG ${ }^{12}$, apresentam o Projeto Pedagógico de Curso (PPC) construído/revisado antes do ano de 2016, aspecto que aponta para a atualização das propostas curriculares da maioria das licenciaturas analisadas. No Quadro 1, organizamos outras informações a respeito das Licenciaturas em Ciências Biológicas das universidades públicas dos Estados que fizeram parte desta pesquisa:

Quadro 1 - Síntese com Informações dos Cursos de Licenciatura em Ciências Biológicas de Universidades Estaduais e Federais dos Estados do Ceará, Paraíba e Rio Grande do Norte

\begin{tabular}{|c|c|c|c|c|c|c|}
\hline Instituição & Nome & $\begin{array}{l}\text { Campus/ } \\
\text { Município }\end{array}$ & $\begin{array}{c}\text { Horário de } \\
\text { Funcionamento }\end{array}$ & $\begin{array}{c}\text { Ano de } \\
\text { Implementação } \\
\text { do PPC }\end{array}$ & $\begin{array}{c}\text { Carga } \\
\text { Horária } \\
\text { do } \\
\text { Curso } \\
\end{array}$ & $\begin{array}{c}\text { Semestres } \\
\text { Letivos para } \\
\text { integralização } \\
\text { curricular } \\
\end{array}$ \\
\hline \multicolumn{7}{|c|}{ Ceará } \\
\hline UFC & $\begin{array}{l}\text { Ciências } \\
\text { Biológicas }\end{array}$ & Fortaleza & $\begin{array}{l}\text { Matutino e } \\
\text { Vespertino }\end{array}$ & 2005 & 3.384 & 8 \\
\hline UNILAB & $\begin{array}{c}\text { Ciências } \\
\text { Biológicas }\end{array}$ & Redenção & $\begin{array}{l}\text { Matutino e } \\
\text { Vespertino }\end{array}$ & 2018 & 3.641 & 9 \\
\hline UFCA & Biologia & Brejo Santo & Noturno & 2017 & 4.200 & 9 \\
\hline \multicolumn{7}{|c|}{ Paraíba } \\
\hline UFCG & $\begin{array}{c}\text { Ciências } \\
\text { Biológicas }\end{array}$ & Cajazeiras & Diurno & 2011 & 2.910 & 8 \\
\hline UFPB & $\begin{array}{l}\text { Ciências } \\
\text { Biológicas }\end{array}$ & João Pessoa & $\begin{array}{l}\text { Matutino, } \\
\text { Vespertino e } \\
\text { Noturno }\end{array}$ & 2019 & 3.540 & 8 \\
\hline UEPB & $\begin{array}{c}\text { Ciências } \\
\text { Biológicas }\end{array}$ & $\begin{array}{c}\text { Campina } \\
\text { Grande }\end{array}$ & Integral & 2016 & $3.530^{13}$ & 10 \\
\hline \multicolumn{7}{|c|}{ Rio Grande do Norte } \\
\hline UFRN & $\begin{array}{c}\text { Ciências } \\
\text { Biológicas } \\
\end{array}$ & Natal & $\begin{array}{l}\text { Matutino e } \\
\text { Noturno }\end{array}$ & 2018 & 3.378 & 10 \\
\hline UERN & $\begin{array}{c}\text { Ciências } \\
\text { Biológicas }\end{array}$ & Mossoró & Diurno & 2018 & 3.750 & 8 \\
\hline
\end{tabular}

Fonte: Dados da pesquisa (2020)

Com base nas informações disponíveis no Quadro 1, vemos, outra vez, a necessidade de algumas notas antes de iniciarmos a análise dos currículos oficiais de formação docente. A princípio, realçamos que, dos oito (8) cursos, há uma licenciatura que está registrada no PPC

${ }^{12} \mathrm{Na}$ Licenciatura em Ciências Biológicas da UFC, o PPC disponível na página institucional da graduação data do ano de 2005, porém, há uma matriz curricular existente no site oficial datando do ano de 2014. No estudo, consideramos para análise a matriz curricular presente no Projeto Pedagógico de Curso (PPC), em razão de ela apresentar as ementas dos componentes curriculares. No que toca ao Curso da UFCG (Campus Cajazeiras) analisado, vimos que o valor de horas estipulado para a formação docente é inferior ao que prescrevem as Diretrizes Curriculares para a Formação Inicial de Professores, tanto no que concerne às diretrizes publicadas no ano de 2015, quanto às diretrizes publicadas em 2019. Isso decorre em virtude de o documento curricular se fundamentar nas Diretrizes publicadas em 2002, que demarcavam a quantidade mínima de 2.800 horas de formação docente.

${ }^{13} \mathrm{O}$ PPC também registra o valor de 3.515 horas. 
com a nominação de "Licenciatura em Biologia". Essa característica atesta-se no Curso da UFCA. Acreditamos que a justificativa para a sua nomenclatura não demarcar o termo "Ciências Biológicas" condiz com a proposição da graduação em formar professores somente para o Ensino Médio, não abarcando os anos finais do Ensino Fundamental. Outro aspecto se pauta na questão de os alunos ingressarem no Curso somente após terem concluído a Licenciatura em Ciências da Natureza. O que compreendemos é que a Licenciatura em Biologia se refere a uma habilitação do Curso de Ciências da Natureza. Ao término do primeiro curso, os discentes aproveitam a carga horária vivenciada e migram para a nova formação (na Licenciatura em Biologia), recebendo ao final o grau de Licenciado também em Biologia (UNIVERSIDADE FEDERAL DO CARIRI, 2017).

Por seguinte, notamos que a Licenciatura em Ciências Biológicas da UFC se encontra integrada ao Curso de Bacharelado. No Projeto Pedagógico de Curso (2005), estão interligadas as duas modalidades de graduação (Bacharelado e Licenciatura), aspecto que não identificamos em outros documentos curriculares. Mesmo nas instituições que ofertam também a modalidade de Bacharelado em Ciências Biológicas, como é o caso da UFPB, da UFRN e da UERN, há um PPC para cada modalidade de graduação.

Além dessas notas, nos chamou a atenção o fato de a metade das licenciaturas destinar mais de oito (8) semestres letivos de formação para a integralização curricular. Pensamos que isso ocorre em razão do elevado número de horas enfatizadas à formação docente - cinco (05) licenciaturas registram mais de 3.500 horas. Também notamos que, em dois (2) PPCs (da UFRN e da UEPB), há duas matrizes curriculares em seu interior. Esse aspecto se refere ao fato de os cursos serem ofertados em mais de um turno. Para cada turno, há uma matriz curricular que não difere na quantidade de horas e nem nas disciplinas curriculares, porém, divergem na quantidade de semestres letivos. Neste estudo, consideramos as matrizes para análise com o maior número de semestres.

Quanto à análise curricular, como primeira dimensão, arrolaremos acerca da caracterização das matrizes curriculares dispostas nos Projetos Pedagógicos dos Cursos (PPCs), particularmente no que se refere à organização das disciplinas curriculares que as compõem, com seus conhecimentos e conteúdos curriculares. Sobre essa dimensão, sistematizamos o que encontramos em nove (9) eixos de análise, os quais foram produzidos no momento da coleta dos dados ${ }^{14}$. Vejamos o Quadro 2:

${ }^{14}$ Para a organização dos eixos de análise, tomamos como base as áreas científicas referendadas no Parecer $\mathrm{CNE} / \mathrm{CES}, \mathrm{n}^{\circ} 1.301$, de 06 de novembro de 2001, que auferiu as diretrizes curriculares nacionais específicas para 
Quadro 2 - Organização das Matrizes Curriculares em horas a partir dos Eixos de Análise

\begin{tabular}{|c|c|c|c|c|c|c|c|c|}
\hline \multirow[t]{2}{*}{ Eixos de Análise } & \multicolumn{8}{|c|}{ Licenciaturas em Ciências Biológicas } \\
\hline & UFC & UNILAB & $\overline{\text { UFCA }}$ & $\overline{\mathrm{UFPB}}$ & $\overline{\mathrm{UFCG}}$ & UEPB & UFRN & UERN \\
\hline $\begin{array}{l}\text { Biologia } \\
\text { Molecular } \\
\text { Evolução }\end{array}$ & $\begin{array}{l}320 \\
(9 \%)\end{array}$ & $\begin{array}{l}315 \\
(9 \%)\end{array}$ & $\begin{array}{l}384 \\
(9 \%)\end{array}$ & $\begin{array}{c}555 \\
(16 \%)\end{array}$ & $\begin{array}{c}345 \\
(12 \%)\end{array}$ & $\begin{array}{c}525 \\
(15 \%)\end{array}$ & $\begin{array}{c}510 \\
(15 \%)\end{array}$ & $\begin{array}{c}540 \\
(14 \%)\end{array}$ \\
\hline $\begin{array}{l}\text { Diversidade } \\
\text { Biológica }\end{array}$ & $\begin{array}{c}896 \\
(26 \%)\end{array}$ & $\begin{array}{c}720 \\
(20 \%)\end{array}$ & $\begin{array}{c}576 \\
(14 \%)\end{array}$ & $\begin{array}{c}720 \\
(20 \%)\end{array}$ & $\begin{array}{c}705 \\
(24 \%)\end{array}$ & $\begin{array}{c}915 \\
(26 \%)\end{array}$ & $\begin{array}{c}840 \\
(25 \%)\end{array}$ & $\begin{array}{c}730 \\
(19 \%)\end{array}$ \\
\hline Ecologia & $\begin{array}{c}240 \\
(7 \%)\end{array}$ & $\begin{array}{l}120 \\
(3 \%)\end{array}$ & $\begin{array}{l}128 \\
(3 \%)\end{array}$ & $\begin{array}{l}225 \\
(6 \%)\end{array}$ & $\begin{array}{l}180 \\
(6 \%)\end{array}$ & $\begin{array}{c}195 \\
(6 \%)\end{array}$ & $\begin{array}{c}120 \\
(4 \%)\end{array}$ & $\begin{array}{l}210 \\
(6 \%)\end{array}$ \\
\hline $\begin{array}{l}\text { Fundamentos das } \\
\text { Ciências Exatas e } \\
\text { da Natureza }\end{array}$ & $\begin{array}{c}480 \\
(14 \%)\end{array}$ & $\begin{array}{l}315 \\
(9 \%)\end{array}$ & $\begin{array}{c}800 \\
(19 \%)\end{array}$ & $\begin{array}{l}300 \\
(8 \%)\end{array}$ & $\begin{array}{c}345 \\
(12 \%)\end{array}$ & $\begin{array}{l}300 \\
(8 \%)\end{array}$ & $\begin{array}{c}360 \\
(11 \%)\end{array}$ & $\begin{array}{c}535 \\
(14 \%)\end{array}$ \\
\hline $\begin{array}{l}\text { Fundamentos das } \\
\text { Ciências Sociais e } \\
\text { Humanas }\end{array}$ & $\begin{array}{c}48 \\
(0,7 \%)\end{array}$ & $\begin{array}{c}390 \\
(11 \%)\end{array}$ & $\begin{array}{l}256 \\
(6 \%)\end{array}$ & $\begin{array}{c}240 \\
(7 \%)\end{array}$ & $\begin{array}{c}330 \\
(11 \%)\end{array}$ & $\begin{array}{l}315 \\
(9 \%)\end{array}$ & $\begin{array}{c}60 \\
(2 \%)\end{array}$ & $\begin{array}{l}215 \\
(6 \%)\end{array}$ \\
\hline $\begin{array}{lr}\text { Fundamentos } & \text { da } \\
\text { Educação } & \mathrm{e} \\
\text { Formação } & \\
\text { Pedagógica } & \end{array}$ & $\begin{array}{c}992 \\
(29 \%)\end{array}$ & $\begin{array}{l}1.080 \\
(30 \%)\end{array}$ & $\begin{array}{l}1.472 \\
(35 \%)\end{array}$ & $\begin{array}{l}1.080 \\
(31 \%)\end{array}$ & $\begin{array}{c}645 \\
(22 \%)\end{array}$ & $\begin{array}{c}780 \\
(22 \%)\end{array}$ & $\begin{array}{c}928 \\
(27 \%)\end{array}$ & $\begin{array}{c}930 \\
(25 \%)\end{array}$ \\
\hline Estudos Optativos & $\begin{array}{c}192 \\
(6 \%)\end{array}$ & $\begin{array}{c}90 \\
(2 \%)\end{array}$ & $\begin{array}{l}256 \\
(6 \%)\end{array}$ & $\begin{array}{c}180 \\
(5 \%)\end{array}$ & $\begin{array}{c}90 \\
(3 \%)\end{array}$ & $\begin{array}{c}180 \\
(5 \%)\end{array}$ & $\begin{array}{c}360 \\
(11 \%)\end{array}$ & $\begin{array}{c}120 \\
(3 \%)\end{array}$ \\
\hline $\begin{array}{ll}\text { Trabalho } & \text { de } \\
\text { Conclusão } & \text { de } \\
\text { Curso (TCC) } & \\
\end{array}$ & $\begin{array}{c}16 \\
(0,3 \%)\end{array}$ & $\begin{array}{c}45 \\
(1 \%)\end{array}$ & $\begin{array}{l}128 \\
(3 \%)\end{array}$ & $\begin{array}{c}30 \\
(1 \%)\end{array}$ & $\begin{array}{c}60 \\
(2 \%)\end{array}$ & $\begin{array}{l}120 \\
(3 \%)\end{array}$ & - & $\begin{array}{l}210 \\
(6 \%)\end{array}$ \\
\hline $\begin{array}{l}\text { Atividades } \\
\text { Complementares }\end{array}$ & $\begin{array}{l}200 \\
(6 \%)\end{array}$ & $\begin{array}{c}566 \\
(16 \%)\end{array}$ & $\begin{array}{l}200 \\
(5 \%)\end{array}$ & $\begin{array}{l}210 \\
(6 \%)\end{array}$ & $\begin{array}{l}210 \\
(7 \%)\end{array}$ & $\begin{array}{l}200 \\
(6 \%)\end{array}$ & $\begin{array}{c}200 \\
(6 \%)\end{array}$ & $260(7 \%)$ \\
\hline Total de Horas & 3.384 & 3.641 & 4.200 & 3.540 & 2.910 & 3.530 & 3.378 & 3.750 \\
\hline
\end{tabular}

Fonte: Dados da pesquisa (2020)

No primeiro eixo de análise, Biologia Celular, Molecular e Evolução, alocamos as disciplinas curriculares que atestam conhecimentos e conteúdos curriculares acerca da organização e interações biológicas e evolutivas, fundamentando-se nas áreas de Bioquímica, Genética, Imunologia, Biologia Celular e Molecular, Embriologia, Histologia e Microbiologia (BRASIL, 2001). A partir do cenário encontrado nos currículos oficiais, compreendemos que há uma presença frequente de disciplinas do referido eixo nas matrizes curriculares de todos os cursos analisados. Dos nove (9) eixos, ele é o terceiro, em termos quantitativos, com mais disciplinas nos documentos oficiais. Em uma perspectiva percentual, sua presença varia entre $9 \%$ a $16 \%$ do total de horas destinadas à formação docente nas graduações. As Licenciaturas 
em Ciências Biológicas da UFPB (16\%), UEPB (15\%) e UFPB (15\%) são as que destinam maior tempo e o maior número de componentes curriculares para o estudo dos conhecimentos e dos conteúdos curriculares referentes ao eixo em discussão.

O eixo de análise Diversidade Biológica é o segundo eixo hegemônico na maioria das matrizes curriculares analisadas. Nele, se apresentam as disciplinas que auferem conhecimentos e conteúdos curriculares sobre a classificação, filogenia, bem como sobre a organização, etologia, fisiologia e estratégias adaptativas morfofuncionais dos seres vivos (BRASIL, 2001). Dessa forma, as disciplinas de Zoologia, Parasitologia, Anatomia, Sistemática Biológica, Morfologia, Fisiologia, Entomologia, Botânica, entre outras, compuseram esse eixo analítico. Com exceção dos cursos da UFCA e da UERN, todas as licenciaturas destinam mais de $20 \%$ de sua carga horária total para o estudo dos conhecimentos e dos conteúdos curriculares que compõem o referido eixo. As graduações da UFC e da UFPB demarcam $26 \%$ de sua carga horária total para as disciplinas do eixo em referência.

No terceiro eixo, Ecologia, acoplamos para a análise os componentes dos currículos oficiais, com os conhecimentos e os conteúdos curriculares que aludem a respeito das relações entre os seres vivos e o ambiente no decurso dos tempos geológicos. Também selecionamos as disciplinas que atentam para os conhecimentos das dinâmicas das populações, das comunidades e dos ecossistemas, da conservação e do manejo da fauna e da flora, bem como da relação saúde, educação e meio ambiente (BRASIL, 2001). Para nossa surpresa, o eixo em análise é o que circunscreve um dos menores números de horas e de disciplinas no interior das propostas curriculares. Nas Licenciaturas em Ciências Biológicas da UFC, da UERN e da UFRN, há somente duas disciplinas (cada uma composta por 60 horas de estudos) que contemplam os conhecimentos e os conteúdos curriculares pontificados nesse eixo.

O eixo de análise Fundamentos das Ciências Exatas e da Natureza é composto por componentes curriculares que pautam sobre os conhecimentos e os conteúdos curriculares da Matemática, Estatística, Química, Física, Geologia, entre outras. Nele, estão as disciplinas que agrupam os conhecimentos e os conteúdos dos currículos essenciais para o entendimento de processos biológicos que serão estudados pelos formandos ao longo da graduação (BRASIL, 2001). Essas disciplinas, na maioria das vezes, aparecem nos semestres/períodos iniciais de formação docente. Nas matrizes curriculares analisadas, identificamos que a prevalência desse eixo analítico diz respeito a $8 \%$ a $19 \%$ do total de horas do currículo oficial. Uma característica peculiar ao referido eixo condiz à Licenciatura da UFCA que, diferentemente das demais, apresenta 800 horas de formação docente na matriz curricular para os 
conhecimentos e os conteúdos curriculares das disciplinas referendadas nesse eixo, aparecendo como o segundo eixo com maior atenção no currículo da graduação. Pensamos que isso se efetua em razão de o Curso estar associado à Licenciatura em Ciências da Natureza, conforme destacamos em momento anterior do texto.

No eixo de análise Fundamentos das Ciências Sociais e Humanas, estão alocadas as disciplinas com os conhecimentos e os conteúdos curriculares das áreas de Sociologia, Língua Portuguesa, Língua Brasileira de Sinais (LIBRAS), Filosofia, História, Metodologia Científica e Filosofia da Ciência, Antropologia e Geografia. No contexto das matrizes curriculares, esse é um dos eixos com menos prevalência de horas na carga horária total dos cursos (varia de $0,7 \%$ a $11 \%$ ) e de componentes curriculares. Na Licenciatura em Ciências Biológicas da UFRN, por exemplo, há uma única disciplina (a disciplina de LIBRAS) na proposta curricular de formação docente que se associa ao eixo em ênfase.

O sexto eixo, Fundamentos da Educação e Formação Pedagógica, concentra as disciplinas com os conhecimentos e os conteúdos curriculares da área de Educação (ou de áreas que se associam à Educação, tais como Filosofia da Educação, Psicologia da Educação, entre outras) e/ou que se perspectivam, mais diretamente, à formação do professor para o ensino de ciências e biologia. Notificamos que a área de Estágio Supervisionado foi considerada nesse eixo analítico. Pela realidade curricular existente nos documentos oficiais estudados, verificamos que, em seis (6) cursos, o eixo em discussão é hegemônico nas matrizes curriculares. Somente as Licenciaturas da UFCG e UEPB não demarcam essa característica, porém, temos que validar que as horas destinadas ao Estágio Supervisionado pesa para esse cenário. Sem esse fator, o número de horas destinadas à formação docente para o ensino de ciências e biologia, bem como a quantidade de disciplinas curriculares com esse objetivo, seria muito inferior.

No sétimo eixo, Estudos Optativos, organizamos as disciplinas validadas nos textos curriculares como opcionais aos discentes, mas que devem ser computadas na carga horária total da formação. As áreas dessas disciplinas não se encontram demarcadas, já que podem estar vinculadas a áreas de qualquer eixo de análise apresentado anteriormente, porém, validamos que há ênfase nos currículos oficiais analisados nas disciplinas específicas da Biologia. O percentual de tempo para estudos dessas disciplinas varia entre $2 \%$ a $11 \%$.

O penúltimo eixo analítico, Trabalho de Conclusão de Curso, formado por disciplinas que visam ao estudo conclusivo/monográfico na Licenciatura, é o que se situa nas matrizes curriculares com o menor tempo destinado para a formação docente. O percentual mínimo encontrado condiz com $0,3 \%$ da carga horária total do curso (da UFC) e o máximo se refere a 
11\% (da UERN). É importante registrar que, na Licenciatura em Ciências Biológicas da UFRN, não há indicação de horas ou atividade concernente ao Trabalho de Conclusão de Curso (TCC).

No nono eixo de análise, Atividades Complementares, estão as indicações de atividades integradoras dos currículos para serem experienciadas no decurso da formação profissional dos licenciandos. Mesmo não se referindo ao estudo em disciplinas curriculares, essas atividades se referem à participação em projetos de pesquisa, ensino e extensão relacionados, principalmente, ao estudo da docência. Nesse contexto, são também validadas uma gama de possibilidades, tais como a participação em monitoria acadêmica e em eventos científicos e culturais, entre outros.

Lembramos que as atividades complementares são orientadas pelas Diretrizes Curriculares Nacionais para a Formação Inicial Docente (BRASIL, 2002; BRASIL, 2015; BRASIL, 2019). Encaminham-se 200 horas de atividades para serem contempladas nos processos de formação inicial dos professores. Nesse eixo de análise, Atividades Complementares, verificamos que todos os cursos analisados atendem a esse preceito curricular, sendo que os percentuais de horas nas licenciaturas variam entre $6 \%$ e $16 \%$ da carga horária geral. Um aspecto que merece ênfase pauta-se na realidade do Curso da UNILAB, pois sua proposta curricular destina 566 horas $^{15}$ ao eixo em análise, número elevado se comparado às demais licenciaturas.

Ao término da caracterização acerca da organização das matrizes curriculares dos cursos analisados, apresentaremos algumas considerações como modo de sumarizar nossa análise:

a) Independentemente de as matrizes curriculares concentrarem um número significativo de horas para o estudo dos fundamentos da Educação e da formação pedagógica, no nosso entendimento, é necessário rever a organização/distribuição dos conhecimentos e dos conteúdos curriculares referentes a essa dimensão no interior dos currículos oficiais das Licenciaturas.

Esse entendimento encontra respaldo no que prescreve a Resolução $\mathrm{CNE} / \mathrm{CP}^{0}{ }^{2}$, de 20 de dezembro de 2019, mais precisamente no que se refere à organização dos currículos dos

\footnotetext{
${ }^{15}$ As atividades complementares na Licenciatura em Ciências Biológicas da UNILAB se encontram organizadas no currículo oficial em um núcleo formativo nominado de "Núcleo de Estudos Integradores para Enriquecimento Curricular". Nele, se apresentam duas modalidades, a saber: atividades complementares e atividades de extensão. As duas modalidades contemplam o que entendemos neste texto como as atividades complementares, somando juntas 566 horas.
} 
cursos de licenciatura. Na normativa curricular, indica-se o total de 3.200 (três mil e duzentas) horas para a formação docente distribuídas em três grupos. O documento encaminha:

Art. 11. A referida carga horária dos cursos de licenciatura deve ter a seguinte distribuição:

I - Grupo I: 800 (oitocentas) horas, para a base comum que compreende os conhecimentos científicos, educacionais e pedagógicos e fundamentam a educação e suas articulações com os sistemas, as escolas e as práticas educacionais.

II - Grupo II: 1.600 (mil e seiscentas) horas, para a aprendizagem dos conteúdos específicos das áreas, componentes, unidades temáticas e objetos de conhecimento da BNCC, e para o domínio pedagógico desses conteúdos.

III - Grupo III: 800 (oitocentas) horas, prática pedagógica, assim distribuídas:

a) 400 (quatrocentas) horas para o estágio supervisionado, em situação real de trabalho em escola, segundo o Projeto Pedagógico do Curso (PPC) da instituição formadora; e

b) 400 (quatrocentas) horas para a prática dos componentes curriculares dos Grupos I e II, distribuídas ao longo do curso, desde o seu início, segundo o PPC da instituição formadora.

Parágrafo único. Pode haver aproveitamento de formação e de experiências anteriores, desde que desenvolvidas em instituições de ensino e em outras atividades, nos termos do inciso III do Parágrafo único do art. 61 da LDB (Redação dada pela Lei no 12.014, de 6 de agosto de 2009) (BRASIL, 2019).

Compreendemos, a partir da análise dos currículos, que os oito (8) cursos atendem, em maior parte, à normativa acerca da distribuição das horas, dos conhecimentos e dos conteúdos curriculares para os Grupos II e III, porém, no que condiz ao Grupo I, é necessária sua revisão, com mais atenção, nas graduações. Em sete (07) Licenciaturas (UFC, UNILAB, UFPB, UFCG, UEPB, UERN e UFRN), o número superior de 800 horas para o eixo de análise nominado por nós de Fundamentos da Educação e Formação Pedagógica não atende ao que determinam as Diretrizes de 2019, uma vez que, ao subtrairmos as 400 horas para o Estágio Supervisionado, o valor restante de horas para o Grupo I se torna inferior ao que orienta o dispositivo normativo.

b) Nas matrizes curriculares, os eixos de análise Ecologia e Fundamentos das Ciências Sociais e Humanas se apresentam com um número de horas e de disciplinas muito reduzido se comparados aos demais eixos que visam a conhecimentos e conteúdos curriculares específicos das Ciências Biológicas e da área da Educação.

Entendemos que o currículo se constrói, seja no âmbito oficial, seja no praticado, por meio de disputas ideológicas e, muitas vezes, políticas. Ele tem a marca de quem o produziu, não sendo neutro e isento de interesses de quem contribuiu com o seu desenvolvimento (APPLE, 2006; SILVA, 2007; MEDEIROS; AGUIAR, 2018; MEDEIROS; DIAS; 
AMORIM, 2019). Essa afirmativa pode justificar a ausência de disciplinas com conhecimentos e conteúdos curriculares desses dois eixos analíticos nas propostas curriculares. É perceptível, em alguns cursos, a secundarização das disciplinas que os formam. Em realidade, se apresentam soltas nos semestres de formação docente, sem nexo com a totalidade dos currículos.

c) Parece não haver um entendimento consensual acerca do que seria o Trabalho de Conclusão de Curso (TCC) nos currículos analisados, bem como da importância da Pesquisa em Educação na formação docente.

Essas considerações se alicerçam na constatação de que, em alguns cursos, a exemplo da UFC, UNILAB, UFPB e UFCG, o tempo destinado à construção do TCC é muito reduzido. No Curso da UFRN, inexiste menção na matriz curricular referente a esse aspecto. A Pesquisa em Educação, similarmente, aparece como um apêndice (algumas vezes existente em uma disciplina) da formação docente vinculada às disciplinas de Metodologia Científica no início dos Cursos.

É sabido, em estudos da área de Educação, que a pesquisa deve ocupar um lugar central na formação de professores da Educação Básica (SOUZA; FAZENDA, 2017; MEDEIROS, 2019). Afinal, além de ela ser um dispositivo que permite a produção de conhecimentos a respeito da realidade educacional e escolar, ajuda no desenvolvimento crítico dos sujeitos em formação (MICHELS; BARBOSA; FARIAS, 2017). Na Educação Superior, nas diferentes modalidades de cursos (Bacharelado, Licenciatura e Tecnológico), a pesquisa é entendida como uma referência à qualificação do alunado.

Apesar dessas considerações, não podemos negar que os currículos analisados também referenciam uma pluralidade de disciplinas com conhecimentos e conteúdos curriculares. Se forem materializadas nos currículos em sala de aula nas universidades de forma contextualizada, somarão muito para uma boa qualificação dos professores para o ensino de ciências e biologia na Educação Básica.

$\mathrm{Na}$ continuidade da análise, evidenciaremos, a partir de agora, a organização, nas matrizes dos currículos oficiais, das disciplinas curriculares voltadas, especificamente, à formação pedagógica para o ensino de ciências e biologia nos anos finais do Ensino Fundamental e no Ensino Médio. Para isso, tomamos como indicação a distribuição das disciplinas em dois eixos principais, quais sejam: Formação Pedagógica e Formação em Educação. 
Declaramos que a organização das disciplinas curriculares com foco na formação pedagógica para o ensino de ciências e biologia nos anos finais do Ensino Fundamental e no Ensino Médio emergiu do eixo apresentado anteriormente na análise, vale lembrar, Fundamentos da Educação e Formação Pedagógica. A partir das disciplinas apresentadas em seu interior, classificamos os dois novos eixos (Formação Pedagógica e Formação em Educação). Para o primeiro, Formação Pedagógica, creditamos as disciplinas que enfocam mais centralmente o ensino de ciências e biologia nos anos finais do Ensino Fundamental e no Ensino Médio; para o segundo, Formação em Educação, consideramos as disciplinas que encaminham atenção à formação docente em uma perspectiva mais geral, as quais atentam às questões para além do ensino em sala de aula.

O Estágio Supervisionado, nesse contexto, foi considerado no segundo eixo, uma vez que entendemos que sua contribuição nos processos de formação docente não condiz, exclusivamente, com as questões de ensino. No nosso ponto de vista, o estágio permite uma leitura plural da Educação (MEDEIROS; CASTRO, 2020). No Gráfico 1, sistematizamos a organização das disciplinas quanto ao total de horas destinadas à formação pedagógica para o ensino de ciências e biologia nos anos finais do Ensino Fundamental e no Ensino Médio nos dois eixos analíticos - Formação Pedagógica e Formação em Educação:

Gráfico 1 - Organização das Disciplinas quanto ao total de horas para a Formação Pedagógica para o Ensino de Ciências e Biologia nos anos finais do Ensino Fundamental e no Ensino Médio

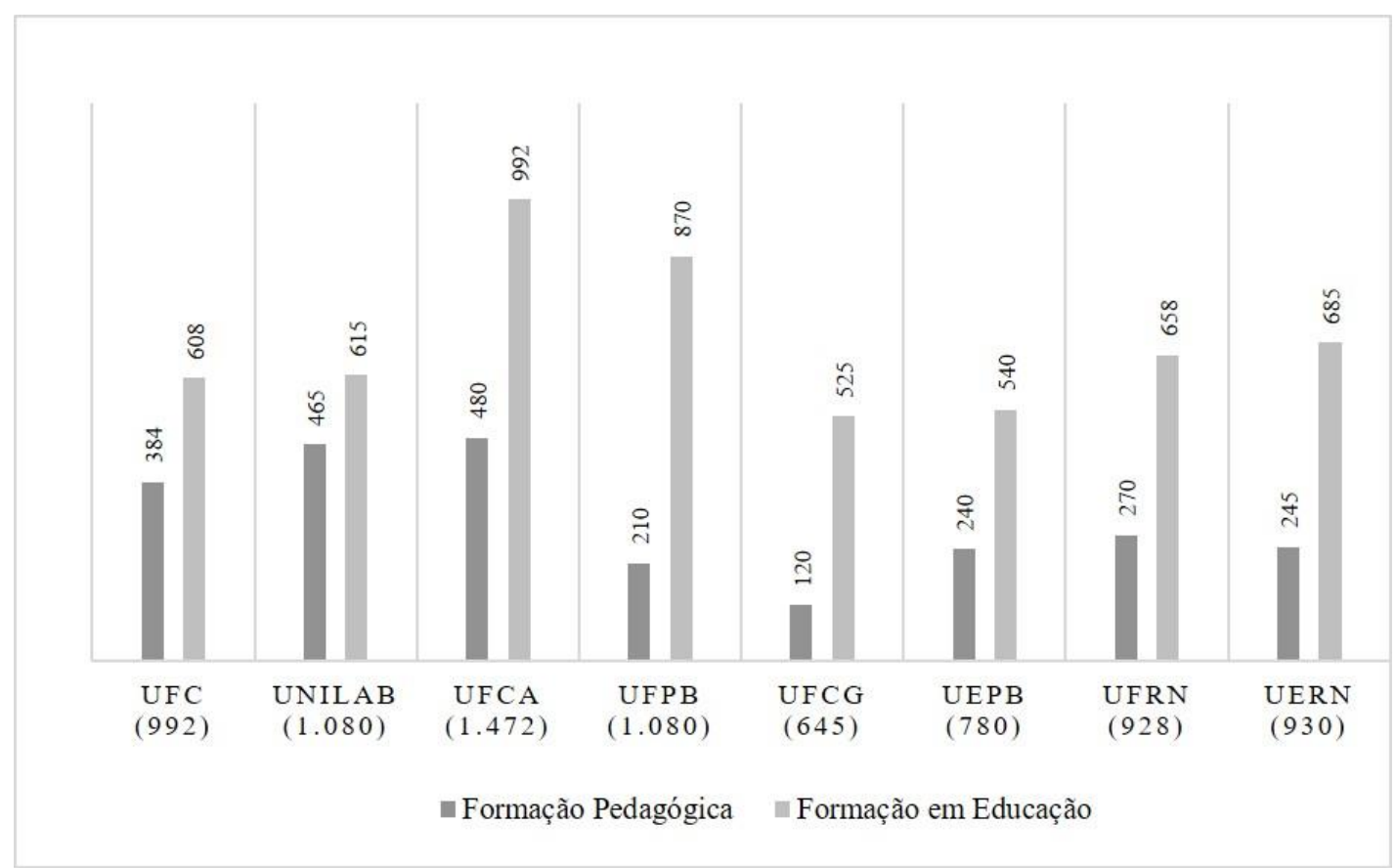

Fonte: Dados da pesquisa (2020)

RIAEE - Revista Ibero-Americana de Estudos em Educação, Araraquara, v. 15, n. 4, p. 1967-1990, out./dez. 2020. e-ISSN: 1982-5587. 
Os dados apresentados no Gráfico 1 oportunizam o entendimento de que as disciplinas consideradas para a formação pedagógica para o ensino de ciências e biologia nos anos finais do Ensino Fundamental e no Ensino Médio estão circunscritas, com maior tempo, ao eixo de análise Formação em Educação. Ele é superior, em termos de horas, à formação docente, quando comparado ao eixo de análise Formação Pedagógica. Afirmamos que em cada matriz curricular há uma realidade diferente, no sentido das disciplinas e das áreas que envolvem os dois eixos em discussão, bem como ao total de horas que comportam.

No Curso da UERN, por exemplo, as disciplinas para a formação pedagógica contemplam 930 horas. Desse valor, 685 horas são pontificadas para o eixo de análise Formação em Educação, com as disciplinas "Organização da Educação Brasileira", "Fundamentos da Educação", "Psicologia do Desenvolvimento e da Aprendizagem da Criança", "Psicologia do Desenvolvimento e da Aprendizagem do Adolescente e Adulto" e "Estágios Supervisionados". Do eixo Formação Pedagógica, 245 horas fazem parte as disciplinas de "Introdução à Didática", "Instrumentação para o Ensino de Ciências Biológicas", "Didática das Ciências Biológicas", "Didática das Ciências Naturais", entre outras (UNIVERSIDADE DO ESTADO DO RIO GRANDE DO NORTE, 2018).

Pelo exemplo citado na Licenciatura em Ciências Biológicas da UERN, as nomenclaturas das disciplinas destinadas à formação pedagógica, em determinadas circunstâncias, abordam as ciências biológicas e, em outras, destacam as ciências da natureza. As expressões "Ensino de Biologia" e "Ensino de Ciências" são também enfatizadas nos nomes das disciplinas em algumas matrizes curriculares (UFCA, UNILAB, UFC, UFCG, UFPB, UEPB e UFRN).

Em relação às áreas e/ou às disciplinas que compõem cada eixo, vimos, com peso, no eixo Formação em Educação, as áreas e/ou os componentes curriculares de "Organização da Educação Brasileira", "Psicologia da Educação", "Política Educacional”, "Informática na Educação", "Estudos sócio-históricos e culturais da Educação", "Gestão Educacional”, "Educação Especial”, "Educação de Jovens e Adultos", "Fundamentos Antro-fílosóficos da Educação", "Formação Docente em Ciências Biológicas", "Organização do Trabalho na Escola e Currículo" e "Estágios Supervisionados".

De forma geral, no eixo de análise Formação em Educação, a ênfase está nos Estágios Supervisionados e nas áreas e/ou disciplinas que se associam à Educação com vistas a contribuir com conhecimentos e conteúdos curriculares de cunho histórico, sociológico, antropológico, filosófico, da psicologia, da política educacional, da organização dos sistemas de ensino e do currículo, bem como da gestão em Educação. 
No que diz respeito ao eixo de análise Formação Pedagógica, as áreas e/ou disciplinas que mais aparecem são "Metodologia do Ensino de Ciências", "Didática", "Didática Específica para o Ensino de Ciências e Biologia", "Práticas Educativas", "Instrumentação para o Ensino de Ciências Biológicas", "Instrumentação para o Ensino de Ciências”, "Instrumentação para o Ensino de Biologia”, “Tecnologias e Materiais Didáticos”, “Avaliação da Aprendizagem" e "Laboratórios de Práticas Pedagógicas". Entendemos que essas disciplinas agrupam conhecimentos e conteúdos curriculares que atentam para o saber ensinar. $\mathrm{O}$ foco da formação docente para o ensino de ciências e biologia é contemplado, com maior precisão, em seu interior.

Ditas essas considerações, avaliamos que os currículos oficiais projetam, em parte, uma formação docente para o ensino de ciências e biologia, especialmente nessa dimensão dos currículos oficiais. É nela (eixo de análise Formação Pedagógica) que se encontram fortalecidas as questões que se reportam ao saber ensinar ciências e biologia nos anos finais do Ensino Fundamental e no Ensino Médio. No entanto, para aprofundarmos o debate, vemos, tal como Ayres (2005) e Medeiros e Aguiar (2018), que é preciso analisar como os currículos oficiais se efetuam no contexto de cada graduação. Somente assim, teremos condições de desenvolver novas conclusões.

\section{Considerações finais}

Este texto apresentou uma análise sobre currículos de formação de professores para o ensino de ciências e biologia nos anos finais do Ensino Fundamental e no Ensino Médio. Tomou como referência oito (8) Cursos de Licenciaturas em Ciências Biológicas de universidades públicas (estaduais e federais) dos Estados do Ceará, Paraíba e Rio Grande do Norte. Como considerações apreendidas da análise, destacamos, entre outras:

As matrizes curriculares são compostas por uma variedade de áreas científicas e disciplinas curriculares. Dentre elas, a área de Educação é contemplada com foco nos documentos curriculares. Todavia, sua atenção está, especialmente, nos Estágios Supervisionados. As disciplinas dos eixos de análise Diversidade Biológica e Biologia Celular, Molecular e Evolução também aparecem com maior frequência nos currículos dos cursos.

A formação pedagógica para o ensino de ciências e biologia nos anos finais do Ensino Fundamental e no Ensino Médio é encontrada com maior tempo nas disciplinas curriculares de cunho mais geral da área de Educação. Essas disciplinas concentram conhecimentos e 
conteúdos curriculares do âmbito histórico, sociológico, da psicologia, entre outros, associados à Educação. Nessa discussão, os Estágios Supervisionados também são centrais.

Por fim, os componentes curriculares que apresentam mais atenção acerca do saber ensinar ciências e biologia se referem às disciplinas de metodologia e instrumentação para o ensino de ciências e biologia, didática, didática específica, práticas educativas e laboratórios de práticas pedagógicas. Assim, quando estudarmos a formação docente para o ensino de ciências e biologia, deveremos dar atenção especial a esses componentes dos currículos oficiais.

\section{REFERÊNCIAS}

APPLE, M. A Política do Conhecimento Oficial: faz sentido a ideia de um currículo nacional? In: MOREIRA, A. F. B.; SILVA, T. T. da (Orgs.). Currículo, Cultura e Sociedade. 9. ed. São Paulo, SP: Cortez, 2006. p. 59-92.

AYRES, A. C. B. M. Tensão entre matrizes: um estudo a partir do curso de Ciências Biológicas da faculdade de Formação de Professores / UERJ. 2005. 249 f. Tese (Doutorado em Educação) - Universidade Federal Fluminense, Niterói, 2005.

AYRES, A. C. B. M.; SELLES, S. E. História da formação de professores: diálogos com a disciplina escolar de ciências no ensino fundamental. Ensaio, v. 14, n. 2, p. 51-66, 2012.

BRASIL. Parecer CNE/CES n. 1.301, de 06 de novembro de 2001. Disponível em: http://portal.mec.gov.br/component/content/article?id=12991. Acesso em: 28 abr. 2020.

BRASIL. Resolução CNE/CP n. 02, de 01 de julho de 2015. Disponível em: http://pronacampo.mec.gov.br/images/pdf/res_cne_cp_02_03072015.pdf. Acesso em: 28 abr. 2020.

BRASIL. Resolução CNE/CP n. 02, de 20 de dezembro de 2019. Disponível em: http://portal.mec.gov.br/component/content/article?id=12991. Acesso em: 28 abr. 2020.

BRASIL. Resolução CNE/CP n. 1, de 18 de fevereiro de 2002. Disponível em: http://portal.mec.gov.br/seesp/arquivos/pdf/res1_2.pdf. Acesso em: 28 abr. 2020.

BRASIL. Resolução CNE/CP n. 2, de 19 de fevereiro de 2002. Disponível em: http://portal.mec.gov.br/component/content/article?id=12991. Acesso em: 28 abr. 2020.

Disponível em: http://proreitorias.uepb.edu.br/prograd/cursos-de-graduacao/. Acesso em: 12 ago. 2020.

DOURADO, L. F. Diretrizes Curriculares Nacionais para a formação inicial e continuada dos profissionais do Magistério da Educação Básica: concepções e desafios. Educação \& Sociedade, Campinas, v. 36, n. 131, p. 299-324, abr./jun. 2015. 
FEITOSA, R.A. O Currículo como Mandala: um estudo de caso sobre a formação do licenciado em Ciências Biológicas. 2014. 265 f. Tese (Doutorado em Educação) Universidade Federal do Ceará, Fortaleza, 2014.

GATTI, B. A.; BARRETTO, E. S. de S. Professores do Brasil: impasses e desafios. Brasília, DF: Editora da UNESCO, 2009.

GATTI, B.A.; NUNES, M. M. R. Formação de professores para o Ensino Fundamental: estudo de currículos das licenciaturas em pedagogia, língua portuguesa, matemática e ciências biológicas. São Paulo: FCC/DPE, 2009.

MEDEIROS, E, A, de; AGUIAR, A, L, O. Formação inicial de professores da educação básica em licenciaturas de universidades públicas do Rio Grande do Norte: estudo de currículos e suas matrizes curriculares. Revista Ibero-Americana de Estudos em Educação, Araraquara, v. 13, n. 03, p. 1028-1049, jul./set. 2018.

MEDEIROS, E. A. de. Formação interdisciplinar de professores: estudo pedagógicocurricular sobre a Licenciatura em Educação do Campo da Universidade Federal Rural do Semi-Árido. 2019. 661 f. Tese (Doutorado em Educação) - Universidade Estadual do Ceará, Fortaleza, 2019.

MEDEIROS, E. A. de; CASTRO, K. K. V. de. O Estágio Supervisionado na área de Gestão Escolar na LEDOC/UFERSA - dispositivo de formação e desenvolvimento profissional docente. Revista Cocar, Edição Especial, v. 08. p. 219-241, jan./abr. 2020.

MEDEIROS, E. A. de; DIAS, A. M. I.; AMORIM, G. C. C. Notas sobre o currículo e a formação interdisciplinar de professores da Educação Básica. Imagens da Educação, v. 9, n. 2, p. 62-77, 2019.

MEDEIROS, J. B. L. de P. Significados e Sentidos do Currículo de Licenciatura: o que dizem professores formadores de um curso de ciências biológicas. 2017. 288 f. Tese (Doutorado em Educação) - Universidade Estadual do Ceará, Fortaleza, 2017.

MICHELS, J.; BARBOSA, G. V.; FARIAS, M. E. Educar pela Pesquisa na Disciplina de Seminário Integrado: um olhar diferenciado sobre o Ensino Médio noturno. Revista IberoAmericana de Estudos em Educação, v. 12, n. 2, p. 933-951, 2017.

REIS, R. de C.; MORTIMER, E. F. Um estudo sobre Licenciaturas em Ciências da Natureza no Brasil. Educação em Revista, v. 36, n. e205692, p. 1-13, 2020.

SACRISTÁN, J. G. O que significa o currículo? In: SACRISTÁN, J. G. (Org.). Saberes e Incertezas sobre o currículo. Porto Alegre: Penso, 2013. p. 16-37.

SILVA, T. M. N. A construção do currículo na sala de aula: o professor como pesquisador. São Paulo: EPU, 1990.

SILVA, T. T. Documentos de identidade: uma introdução às teorias do currículo. 2. ed. Belo Horizonte: Autêntica. 2007. 
SOUZA, M. A. de; FAZENDA, I. C. A. Interdisciplinaridade, currículo e tecnologia: um estudo sobre práticas pedagógicas no Ensino Fundamental. Revista Ibero-Americana de Estudos em Educação, v. 12, n. 2, p. 708-721, mar. 2017.

TOMITA, N. De História Natural a Ciências Biológicas. Ciência e Cultura, v. 47, n. 12, p. 1173-1177, dez. 1990.

UNIVERSIDADE DA INTEGRAÇÃO INTERNACIONAL DA LUSOFONIA AFROBRASILEIRA. Projeto Pedagógico do Curso de Licenciatura em Ciências Biológicas. Redenção, 2018. (Documento Digital). Disponível em: http://www.unilab.edu.br/cienciasbiologicas-licenciatura/. Acesso em: 12 ago. 2020.

UNIVERSIDADE DO ESTADO DO RIO GRANDE DO NORTE. Projeto Pedagógico do Curso de Licenciatura em Ciências Biológicas. Mossoró, 2018. (Documento Digital). Disponível em: http://proeg.uern.br/default.asp?item=proeg-projetos-pedagogicos-central. Acesso em: 12 ago. 2020.

UNIVERSIDADE ESTADUAL DA PARAÍBA. Projeto Pedagógico do Curso de Licenciatura em Ciências Biológicas. Campina Grande, 2016. (Documento Digital). Disponível em: http://proreitorias.uepb.edu.br/prograd/cursos-de-graduacao/. Acesso em: 12 ago. 2020.

UNIVERSIDADE FEDERAL DA PARAÍBA. Projeto Pedagógico do Curso de Licenciatura em Ciências Biológicas. João Pessoa, 2019. (Documento Digital). Disponível em: https://sigaa.ufpb.br/sigaa/public/curso/ppp.jsf?lc=pt_BR\&id=5505677. Acesso em: 12 ago. 2020.

UNIVERSIDADE FEDERAL DE CAMPINA GRANDE. Projeto Pedagógico do Curso de Licenciatura em Ciências Biológicas. Cajazeiras, 2011. (Documento Digital). Disponível em: http://cfp.ufcg.edu.br/portal/. Acesso em: 12 ago. 2020.

UNIVERSIDADE FEDERAL DO CARIRI. Projeto Pedagógico do Curso de Licenciatura em Biologia. Brejo Santo, 2017. (Documento Digital). Disponível em:

https://www.ufca.edu.br/cursos/graduacao/biologia/. Acesso em: 12 ago. 2020.

UNIVERSIDADE FEDERAL DO CEARÁ. Projeto Pedagógico do Curso de Licenciatura em Ciências Biológicas. Fortaleza, 2005. (Documento Digital). Disponível em:

https://prograd.ufc.br/pt/cursos-de-graduacao/ciencias-biologicas-bacharelado-e-licenciaturafortaleza/. Acesso em: 12 ago. 2020.

UNIVERSIDADE FEDERAL DO RIO GRANDE DO NORTE. Projeto Pedagógico do Curso de Licenciatura em Ciências Biológicas. Natal, 2018. (Documento Digital).

Disponível em:

https://sigaa.ufrn.br/sigaa/public/curso/portal.jsf?id=111635035\&nivel=G\&lc=pt_BR. Acesso em: 12 ago. 2020. 


\section{Como referenciar este artigo}

MEDEIROS, E. A. de; MEDEIROS, M. L. S. de. Licenciaturas em Ciências Biológicas: análise de currículos de formação de professores para o ensino de ciências e biologia. Revista Ibero-Americana de Estudos em Educação, Araraquara, v. 15, n. 4, p. 1967-1990, out./dez. 2020. e-ISSN: 1982-5587. DOI: https://doi.org/10.21723/riaee.v15i4.13642

Submetido em: 02/02/2020

Revisões requeridas em: 30/05/2020

Aprovado em: 25/07/2020

Publicado em: 30/08/2020 